\section{Reducing food waste in food manufacturing companies}

\author{
Paola Garrone, Marco Melacini, Alessandro Perego, Sedef Sert \\ Politecnico di Milano
}

\title{
Abstract
}

Putting unsold food at good use is clearly a high-priority option according to the Food Waste Hierarchy, but we still know relatively little about the antecedents, strategies, and processes that make it possible within companies. This paper aims at explaining how food manufacturers can prevent the degradation of generated surplus food into waste. Based on an extensive literature review and 4 exploratory case studies, research questions are formulated about (i) available avenues for managing surplus food, and (ii) internal drivers that make these avenues viable and efficient. In order to adapt, refine and corroborate the conceptual framework, the research conducts 10 descriptive case studies of Italian food manufacturers. Results from the cross-case analysis highlight the multiplicity of reuse and redistribution options, and their viability over the product shelf life. The analysis also shows that a structured surplus food control system and partnerships with food aid organizations are necessary to reduce food waste.

\section{Keywords}

Surplus food; Food waste; Redistribution; Manufacturing; Food waste hierarchy

Final version published as: Garrone, P., Melacini, M., Perego, A., \& Sert, S. (2016).

Reducing food waste in food manufacturing companies. Journal of cleaner production, 137, 1076-1085. 


\section{Introduction}

After the shocking report of the United Nations' Food and Agriculture Organization (FAO), which stated that, every year, one third of the food produced for human consumption is lost or wasted globally - 1.3 billion tons (Gustavsson et al., 2011) - the world has become more aware of the issue of food waste. Wasting food also means wasting resources such as water, cropland and energy. Indeed, food is wasted throughout the whole supply chain, from agriculture and fishing to the end household consumption (Kummu et al, 2012).

On the other hand, according to FAO statistics, almost 800 million people are undernourished globally (FAO, 2015). Food insecurity is an important issue even in developed countries; in Europe, nearly 43.6 million people were estimated to be food-insecure (Gentilini, 2013) and, at the same time, European countries are reported to generate $179 \mathrm{~kg}$ per capita of food waste per year (O'Connor, 2013).

Although different approaches are followed to achieve food security, such as increasing efficiency in production and distribution, the figures on wasted food speak loudly in favour of reducing food waste, seen as one of the possible options to address this problem. Reducing food waste is a global priority not only to conserve natural resources, but also to deal with food insecurity (Evans et al., 2012; Evans et al., 2013; Garnett, 2014). Waste reduction is connected, in part, with the effective management of surplus food, where surplus food can be defined as "the edible food that is produced, manufactured, retailed or served but for various reasons is not sold to or consumed by the intended customer" (Garrone et al., 2014a). Preventing the generation of surplus food whenever possible and managing it wherever it is created are critical options to reduce food waste degradation.

Surplus food management and its role in the model known as "food waste hierarchy" are discussed in a few articles (Papargyropoulou et al, 2014), but we know relatively little about the operational processes, structural antecedents and intentional strategies that make it both feasible and cost-effective within companies. Redistributing surplus food to food banks and other food aid organizations is highly recommended from a social perspective, but there are very few studies examining the critical factors behind this management channel.

It is now, therefore, necessary to provide companies with innovative operational instruments that can be used to manage surplus food efficiently and effectively, once it is generated. The main aim of this paper is to combine the objectives of reducing waste and enhancing food 
security in an integrated way. The first contribution of this paper is to adapt the food waste hierarchy to food manufacturing companies, refining it by including more pertinent options. The second contribution is to identify in a clear manner the main critical factors that enable food manufacturing companies to set in place an efficient and effective process for managing surplus food and, more particularly, for supplying it to the food assistance sector.

The remainder of this paper is structured as follows. The research background is explained in Section 2 and the research methodology is summarized in Section 3. Section 4 contains the main results of the study. Section 5 includes the discussion of the main conclusions, together with a potential route for future studies.

\section{Background}

Over the past years, the literature on food waste has increased significantly. The issue has been investigated from various angles, including sociological (Evans et al., 2014), policy development (Thyberg \& Tonjes, 2016) and ethical (Edwards \& Mercer, 2008) perspectives. In most studies, food waste is explained by dividing it into different categories (Kantor, et al., 1997; Kummu, et al., 2012) or by directly assessing the value of waste along the food supply chain (Buzby \& Hyman, 2012; Katajajuuri, et al., 2014).

According to the definition given by FAO, food waste "refers to the removal from the food supply chain of food which is fit for consumption, by choice, or which has been left to spoil or expire as a result of negligence by the actor-predominantly, but not exclusively the final consumer at household level” (FAO, 2014, p. 4). On the other hand, we believe that including food fit for consumption within the definition of food waste can hinder the opportunities for reducing food waste degradation. Therefore, we formulated our research by starting from the definition of surplus food, which is explained as "the edible food that is produced, manufactured, retailed or served but for various reasons is not sold to or consumed by the intended customer” (Garrone et al., 2014a).

The European Union Directive 2008/98/EC on waste management laid the foundations for the food waste hierarchy (Papargyropoulou et al, 2014) and set priorities, by suggesting that companies should first of all prevent surplus food from being generated. If feasible, this is clearly the best option.

Although companies do all they can to avoid generating surplus food, in some cases it is unavoidable (Mena et al., 2011; Garrone et al. 2014b; Buzby et al., 2015). 
1 For instance, products that have reached their sell-by date cannot be sold to their intended

2 customers at full price even though they are perfectly edible (Aleksandar \& Smaje, 2008;

3 Garrone et al., 2014a). Processing errors, poor handling and packaging failures, such as wrong labels and damaged boxes (Kantor et al., 1997), are other common reasons for surplus food generated at the manufacturing stage (Richter \& Bokelmann, 2015).

Once generated, surplus food should be "reused" for human consumption (Schneider, 2013). Many scholars associate reusing to donations made to non-profit organizations. Donated surplus food is redistributed to disadvantaged people in different ways that include providing food and grocery products to be prepared and consumed at home or serving meals to be consumed on-site. Apart from a few special cases, the donor (company) cannot reach the persons in need of food aid directly itself and so non-profit organizations are needed to connect both sides of the "supplier” and "receiver” chain (Santini \& Cavicchi, 2014).

If the reuse option is not possible, then the food is no longer suitable for human consumption and should be recycled (Papargyropoulou et al, 2014). Recycling food waste can be defined as "reducing the amount of food waste entering waste stream” (Griffin et al., 2009), for instance, into animal feed or compost (Papargyropoulou et al, 2014). Food waste can also be transformed into valuable materials that can be used in some sectors, especially in the nutraceutical and pharmaceutical industries (Mirabella et al, 2013). Finally, before resorting to its disposal, the suggestion it to recover energy from food waste and reduce any negative environmental impact (Papargyropoulou et al, 2014).

Obviously, sending valuable materials to landfill, incineration or disposal is not a sustainable option for society, the environment and the economy, and consequently is at the bottom of the food waste hierarchy. Some empirical studies, in fact, demonstrate that a reduction of disposed waste may lead to substantial cost savings for companies (Lundie \& Peters, 2004; Darlington et al., 2009).

Although the food waste hierarchy proposes a hierarchical guideline to manage surplus food in the supply chain, from prevention to disposal, applying this framework can follow very different avenues across the product and supply chain stages, depending upon the companies' strategies and capabilities. In other words, applying this policy may not be as straightforward as expected. A second under-studied issue concerns the internal barriers and enablers for surplus food management, looking in particular at the drivers that can increase the amount of food saved for human consumption 
1 The aim of this research is to fill these gaps, i.e. to adopt and enhance the food waste hierarchy and identify the critical factors that affect its implementation, by studying the process of managing surplus food in food manufacturing companies.

Based on literature review, two broad and preliminary questions can be formulated:

- How can food manufacturers implement the food waste hierarchy?

- How can food manufacturers prevent surplus food degrading into food waste?

In order to extrapolate the research questions with greatest potential in terms of management and policy implications, insights from literature reviews are not sufficient and have to be combined with a bottom-up exploration of food manufacturers' strategies and operations concerning surplus food.

\section{Formulation of research questions and research design}

Qualitative research methodologies, such as case studies, can be particularly suitable during the early stages of the investigation of a phenomenon (Eisenhardt, 1989; Yin, 2003). This paper draws on case studies to obtain a conceptual framework of surplus food management in food, that is to refine, corroborate and adapt the very general insights gained through the literature review to the complex reality of food manufacturing. Moreover, a multiple-case study approach is used since the outcomes of multiple-case studies are commonly better grounded than results from single-case studies (Eisenhardt \& Graebner, 2007).

In order to formulate our research questions and design descriptive case studies, we conducted a few exploratory case studies. The literature review proved, in fact, not to be sufficient for elaborating hypotheses on the process used by manufacturers to manage surplus food. In addition, the extant studies could not offer any clear or detailed predictions on the internal barriers and enablers for recovering and redistributing surplus food. We, therefore, combined insights from the literature review with the results from exploratory cases, following Eisenhardt's argument (1989) whereby case studies can be a starting point in developing a theory.

\subsection{Interview protocols}

For both the exploratory and descriptive cases, a confidentiality agreement was offered to all participating companies, since, for many organizations, information on surplus food 
management is highly sensitive. In the description of the sample and the empirical analysis, the companies will be named and referred to with numbers and alphabetical letters. Interviews were not recorded for the same reason, which helped to reduce the response bias of the interviewees.

Each interview lasted around two hours and was conducted by a group of three researchers to reduce personal biases (Voss et al, 2002). Visits and company reports were used as secondary methods for collecting data (Yin, 2003). In general, company tours were a good opportunity to verify and clarify responses given in the interviews and also gave researchers a feel for how the company deals with overall surplus food and waste.

Results from each interview were analyzed, coded and put into a standard template. Each question was formulated as a variable, reducing the data collected through the interviews into categories. By comparing each incident, we set out the properties for each category and the dimensions of these properties (Voss et al., 2002).

\subsection{Exploratory case studies}

Four exploratory cases were conducted to identify the main elements of the conceptual framework, and as the basis for defining the sample and designing the questionnaire for the descriptive cases.

We asked the supply manager and the director of the leading food bank in Italy - the Fondazione Banco Alimentare - to provide a shortlist of five best and five worst cases in surplus food management. At the end of this process, we were able to conduct interviews with four companies willing to be studied (Table 1). Two of them turned out to be long-lasting and regular donors. Another makes donations from time to time and the last is a company that used to supply the food bank, but has recently decided to stop making donations. Therefore, the study involves both active donors and those lagging behind. Looking at the sample's characteristics, it contains producers of fresh food, ambient (or shelf-stable) food and frozen food. 


\begin{tabular}{|c|c|c|}
\hline Case & Main stream products & Domestic Turnover $[\mathrm{m} €]$ \\
\hline C1 & Fresh food & 220 \\
\hline C2 & Frozen and ambient food & 1100 \\
\hline C3 & Ambient food & 190 \\
\hline C4 & Ambient food & 2000 \\
\hline
\end{tabular}

1

2

3

4

5

Unstructured interviews were conducted with the managers responsible for surplus and waste management in order to distinguish the key elements of the conceptual framework from the extreme cases, (Fontana \& Frey, 1994). Although we did not use a questionnaire, the following questions were given beforehand to guide the conversation.

- What are the main causes for surplus food generation in your company?

- How do you manage surplus food? Could you describe the operational process and preferred options?

- In your opinion, what are the key factors to be considered for managing surplus food, once generated, in an efficient and effective way? Which factors prevent degradation of surplus food into food waste?

- What are the internal and external barriers to the redistribution of surplus food for social purposes? And the enablers?

\subsection{Results of exploratory cases and definition of the research questions}

The exploratory cases were analyzed on a case-by-case basis. They revealed that, consistently with the food waste hierarchy, companies start to consider actions for surplus food reuse and redistribution when they detect that there is the risk of generating surplus food. Depending or not on whether it is suitable for human consumption, surplus food is managed according to different approaches.

- $\quad$ Surplus food reuse. Surplus food can still be offered by manufacturers to their intended primary customers via different methods i.e. remanufacturing (C2), repackaging (C2), discounts (C3) and promotions (C3).

- $\quad$ Surplus food redistribution. Surplus food can still be targeted to human consumption even outside the primary markets in many ways, for social or commercial purposes, such as through secondary markets (C3) or by donating to food aid organizations (C2, C3). 
- $\quad$ Food waste management. Not all surplus food is reused or redistributed. In these cases, surplus food becomes waste that needs to be managed (C1). Apart from recycling it into animal feed and fertilizers, recovery can take the forms of energy or material recovery (C4).

Based on these preliminary insights, we can specify a research question concerning the application of food waste hierarchy in manufacturing.

Research question 1: How do food manufacturers implement the food waste hierarchy?

Research question 1a: What are the potential options for reusing and redistributing surplus food?

Research question $1 b$ : What are the main decision-making factors in managing surplus food?

Exploratory case studies and, more specifically, the comparison between the two manufacturers that donate regularly and the two that lag behind, clarified several factors behind the effective and efficient management of surplus food in manufacturing, once it is generated.

- $\quad$ Measurement. Surplus food is managed more effectively if it is measured regularly and communicated to different functions as a key performance indicator (Case C3), otherwise surplus food is not managed and degradation probability increases (Case C1).

- $\quad$ Coordination. Coordination among different company functions regarding surplus food management makes it easier to select the best option, by taking economic, environmental and social perspectives into account (Case C3).

- Organization. Various causes can generate surplus food (Case C2), and making decisions in a timely manner requires designing a process around each of these causes (Case C3).

As far as redistribution to food aid organizations is concerned, the exploratory interviews highlighted the variables that describe a company's relationship with food banks.

- $\quad$ Pro-activism. The company can manage the process proactively (Case C3) or only be reactive when answering the request of non-profit organizations (Case C4).

- Regularity. Donation to food aid organizations can be regular, with the company defining the frequency of its donations jointly with the non-profit organizations (Case C3) or 
1 irregular when the donation is triggered by the detection of surplus food or by a call from the non-profit organization (Case C4).

The research question concerning the drivers of surplus food management was specified as follows.

Research question 2: How do food manufacturers prevent surplus food degrading into food waste?

Research question 2.a: What is the relationship between the prevention of food waste and the management of surplus food; what is the coordination mechanism among the interested functions; and how are surplus food processes managed?

Research question 2.b: What is the relationship between the redistribution of surplus food and partnerships with food aid organizations?

\subsection{Design of descriptive case studies}

The core of our empirical analysis is a cross-case analysis of descriptive case studies. To this purpose, the descriptive case study methodology was designed on the basis of both the literature review and the exploratory stage. A case study protocol was prepared to ensure the reliability of the results by standardizing the investigation (Yin, 2003).

First of all, we adopted the interview protocol described in Section 3.1. Secondly, a semistructured interview questionnaire was developed in three stages. A first draft was prepared on the basis of the literature review and our research questions. This draft was revised by a panel of nine academics and four practitioners operating in food manufacturers and food banks. The first draft was then adapted following their feedback and was piloted in two interviews, after which, a few additional questions were added and others adapted. The final questionnaire covered five key areas:

1. Contact details and characteristics of the company: The first section was designed to collect general information about the company being interviewed. The logistics network and planning process were investigated for each company.

2. Quantitative and qualitative assessment of surplus food generated: This involved collecting information relating to the amount of surplus food generated in the companies and how surplus food is measured. 
1 3. Main reasons for surplus food generation and main management alternatives: The reasons

2 for surplus food generation and the options used to manage surplus food were discussed in the 3 third section.

4 4. Surplus food management process: The fourth section was designed to understand the process of surplus food management. Internal processes and relationships with third parties were discussed in this section.

5. Main motivations, constraints and drivers towards surplus food management: In this section, the focus was on surplus food redistributed for social purposes. The primary motivations, the main internal and external constraints and drivers relating to management and redistribution of surplus were discussed in this section.

More precisely, the first research question is answered by analyzing sections 2, 3 and 4, while the second research question is answered by analyzing sections 4 and 5 .

Finally, we identified the case sample. We followed Eisenhardt's argument (1989) suggesting that a cross-case analysis involving four to ten case studies can be a good basis for analytical generalization and to ensure external validity, and performed a cross-case analysis on ten food manufacturing companies operating in a single region in Northern Italy (Table 2). This helped to reduce the potential impact of environmental factors on the cross-case analysis, e.g. differences in the quality of infrastructure or the different distribution of food aid organizations in the area.

Taking into account the sample characteristics, it is possible to note that our sample contains small, medium and large companies with diverse product ranges. However, all the companies have a relationship with food banks or food aid organizations and all donate different amounts of products according to different schedules. This is consistent with the aim of this research (more particularly, with research question 2). Nonetheless, we are aware that reliance on the food bank as the main source may create a sample selection bias, with a greater incidence of good practice than in the overall industry environment, and we will discuss the results accordingly

Table 2 - Description of the sample 


\begin{tabular}{|c|c|c|}
\hline Case & Main stream products & Domestic turnover $[\mathrm{m} €]$ \\
\hline A & Dairy products & 14 \\
\hline B & Meat products & 180 \\
\hline C & Beverages & 300 \\
\hline D & Dairy products & 220 \\
\hline E & Conserved food products & 1300 \\
\hline F & Fresh products & 100 \\
\hline G & Dairy products & 660 \\
\hline H & Conserved food products & 320 \\
\hline I & Confectionary products & 1000 \\
\hline J & Confectionary products & \\
\hline
\end{tabular}

Following the suggestions of Voss et al (2002), the outline of the questionnaire was sent in advance to help the interviewees be properly prepared. Interviewees were middle or senior managers responsible for logistics and/or surplus food management within their organizations. In some instances, the Corporate Social Responsibility (CSR) manager also took part together with the manager responsible for surplus food. It is known that multiple sources of evidence help to improve the construct's validity (Yin, 2003).

\section{Findings and discussion}

In this section, the research questions are answered, based upon the descriptive cases.

\subsection{Food Waste Hierarchy in food manufacturing}

The main findings relating to the first research question are described in detail in the following paragraphs.

Surplus food reuse - Remaking (Remanufacturing and repackaging). Based on the product type and the reason why surplus food is generated, companies can opt for its remanufacturing in the case of production errors, or repackaging in the case of packaging and labelling errors. In both cases, the remaking must follow control instructions given by the quality department, for safety purposes, and surplus food is reworked and fed back to the primary market. Remanufacturing is used in meat, chocolate and pasta production (Cases B, I and H respectively); it is also true that remanufacturing processes are not feasible or efficient in some of the other sectors analyzed. We, in fact, found that repackaging is a minor option, due to the additional cost of removing the package from the product and repackaging it. As a consequence, it is used by the 
chocolate producer only (Case I), something that can be explained by the higher value of the

2 product. The main functions involved in the remaking process are production and quality.

Surplus food reuse - Sales with promotions and discounts. Despite surplus food being generated, sales on primary markets can still be profitable for companies, especially for chocolate (Case I). When it is clear that there is a risk of reaching the internal sell-by date, the manufacturer can try to sell surplus food to its customers on the primary market at a discounted price (Cases B, C, D, F, G, I and J). Coordination between the sales, marketing and planning departments is crucial for making a timely decision and to sell surplus food to the company's intended customers (Case I). The option of selling on primary markets tends to expire rapidly, and only a few customers will accept the trade-off between short shelf life and reduced price (Case D).

Surplus food redistribution - Sales in secondary markets. When the surplus food can no longer be sold on the primary channels, some companies will use secondary channels, i.e. alternative markets like distributors specializing in surplus products (Cases B, C, D, F, and G) or special points of sale managed directly by the company (Case I). Revenue from secondary markets was found to be substantial in only one of our cases (Case F). The main functions involved here are sales, marketing, planning and finance.

Surplus food redistribution - Marketing actions and sponsorships. Companies can also utilize surplus food by sponsoring specific organizations or arranging product tasting events. In Case I, the company department responsible for surplus food management checks whether employees have submitted any sponsorship requests to the CSR department/officer. The company allows its employees to sponsor and to suggest events to be sponsored. These can be charitable events or sports competitions where surplus food is offered to participants.

Surplus food redistribution - Internal distribution. Companies can also choose to distribute surplus products within their organization. In general, they set up a dedicated area stocked with "free to take" products available to their employees. For instance, in Case A, the company produces yogurt. When production changes from one flavour to another, the set-up batch will be mixed (e.g. a combined banana and strawberry flavour). Products from this batch are absolutely edible but cannot be sold. Instead of disposing of them, the company will pack and gift these products to their employees. The main functions involved here are quality control, planning and operations. 
1 Surplus food redistribution - Donation: Surplus food can be given for free to non-profit organizations that assist the poor. The beneficiaries can be front-end aid organizations that serve food to people with insecure residency status or other people in need (organizations can be social supermarkets, food pantries or soup kitchens, social coffee shops and social restaurants), or a back-end, wholesale organization that supplies to front-end aid organizations (such as food banks). Given the approach followed in selecting the sample (Section 3), all the companies interviewed use this channel. In many cases, food manufacturers prefer to work with a single established food aid organization (Cases A, C, E, F, G, and H). In some cases, however, a second food aid organization becomes involved, because the first organization's collection capacity or demand for certain types of goods can be limited (Case B, D, I, and J). If food aid organizations arrange product transport, the donation is easier from the company's perspective. However, in Case E, the company uses its own transport methods to help the non-profit organization with the collection of goods. The main functions involved in the donation decisions here are supply chain and logistics, planning and operations and CSR.

Food waste management - Conferment to processing companies. Depending on the product type, surplus food can be sold to companies that produce animal feed or fertilizers. In some cases, the company can earn a small revenue from this channel. In Case D, most of the company's surplus food is sold to produce animal feed. The company has a close relationship with an animal feed producer and the product is suitable (i.e. yogurt and milk). This is not an option for meat producers, because of safety regulations on animal feed processing (Case B).

Food waste management - Conferment to waste management companies. At the bottom of the hierarchy, conferment of food waste to third parties for disposal, with or without recovering energy, is the final option (Cases B, C, E, G, I, and J). Typically, a specialized waste management utility or company collects and treats waste produced by food manufacturers. In all cases, waste management is a cost for the company. Cost control implies that this waste has to be held at the minimum level.

\subsection{Critical factors for surplus food management}

\subsubsection{Management control system for surplus food: methods and functions}

The main findings relating to research question (2a) are summarized as follows.

Measurement. Three levels of measurement were detected: 
- Ad hoc measurement: Some companies measure surplus food only if the amount generated is extremely high due to extraordinary events like failed promotions or unsuccessful new product introductions (Cases B, D, and G).

- Periodic and fragmented measurement: Some companies measure and monitor surplus food regularly, where different corporate functions are involved depending on the types of surplus food. For instance, the marketing department can manage commercial returns, while management control monitors the products sent to landfill (Cases E and $\mathrm{J})$.

- Periodic and structured measurement: Some companies measure and monitor surplus food regularly, with standard surplus food measurement indicators in all departments (A, C, F, H, and I).

Coordination. The process for managing surplus food involves various business functions, i.e. quality control, production, planning and operations, supply chain and logistics, marketing, external relations and CSR. In the exploratory cases, the companies with a formal surplus food management process stated that different company functions interact with each other regularly to decide how to manage surplus food. Three levels of coordination were detected:

- No coordination: no joint decisions made among the various departments, and the whole process is managed by a single department without consulting the others (Cases B, D, and G).

- Informal coordination: the departments are in contact by email, phone and meet informally when necessary to make decisions (Cases C, E, and J).

- Formal coordination: surplus food is managed through regular meetings involving different departments (Cases A, F, H, and I).

Organization. There are different reasons behind the generation of surplus food and the different methods for managing it depend upon these reasons. For instance, if surplus food is generated as the result of error, the company can decide to go along the route of remanufacturing. Similarly, repackaging may be used for labelling and packaging errors. When surplus food is the result of imminent internal sell-by dates, the company can try to sell the food to its customers on the primary market at a discounted price. It can then follow the various routes described previously. Three levels of process organization were detected: 
- Process not organized: Some companies have no procedure in place for the different causes of surplus food generation (Case D).

- Process organized for some causes: Some companies have a formal approach for some causes of surplus food generation, such as exceeding the internal sell-by date (Cases B, C, E, G, H, and I)

- Process organized for all causes: Some companies have a formal approach for all causes of surplus food generation (Cases A, F, and J).

Table 3 compares cases for the three components of the management control system

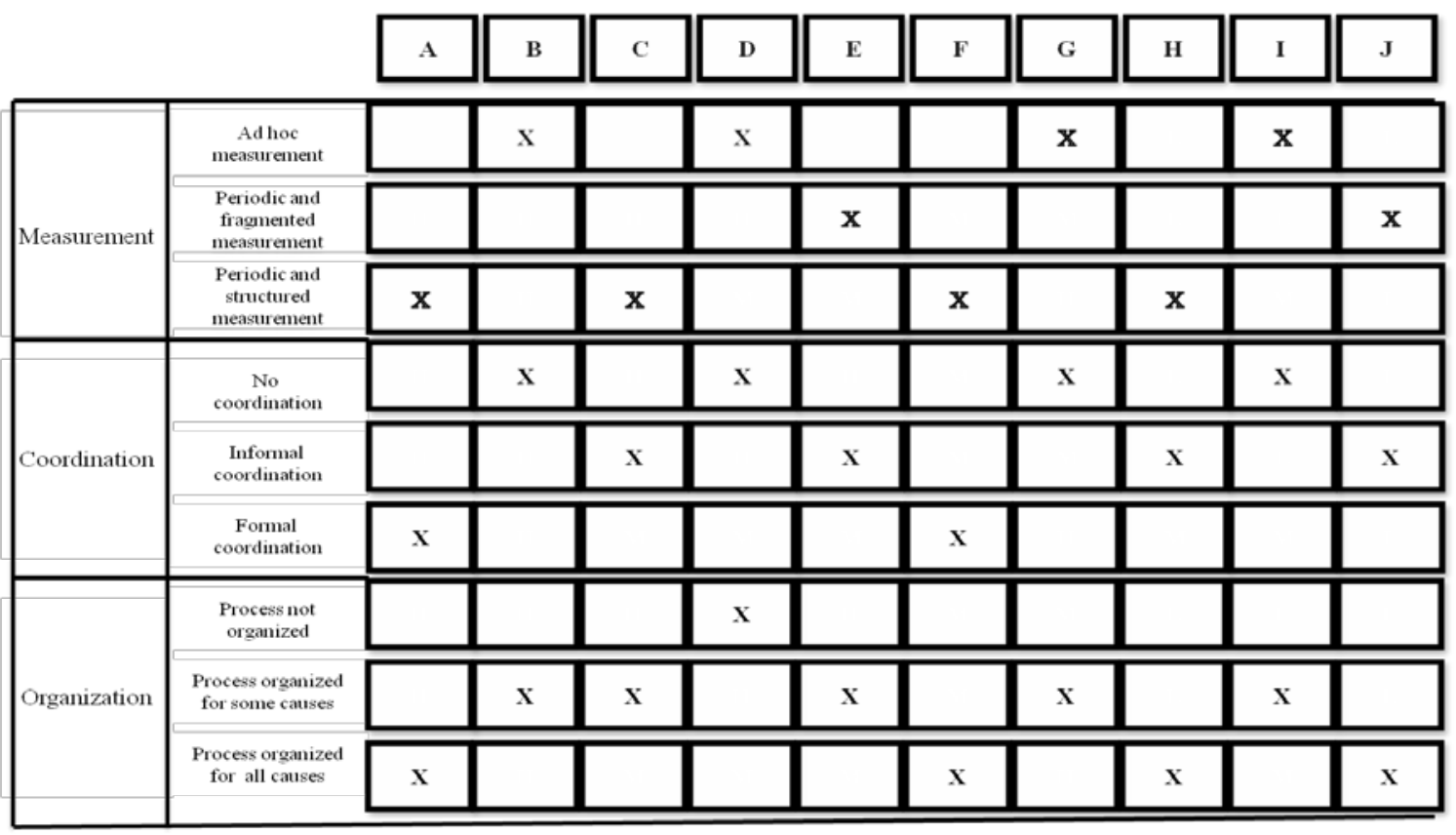

In order to perform the cross case analysis, we used an ordinal scale with three options, Low (L), Medium (M) and High (H), to indicate how strongly each factor is implemented by the individual manufacturers. (Example: Companies using ad hoc measurement systems are classified as Low (L) for the measurement parameter.) Then, in order to compare the cases, the three components used to assess "management control" were reduced to a single parameter. The logic applied here is as follows. An overall High level of management control was assigned if the entire management control system contained at least two components assessed as High and none assessed as Low. An overall Low level of management control was assigned if the entire management control system contained at least two components assessed as Low and none assessed as High. All the remaining cases were labelled as Medium (Table 4). 
1 The effectiveness of surplus food management is measured, in each case, through the proportion

2 of surplus food recovered for human consumption, i.e. reused or redistributed, out of the total

3 surplus food generated. The cross-case analysis allows us to deduce how surplus food savings

4 vary according to how committed manufacturers are to managing the problem. A clear

5 correlation is found between the commitment to surplus food management and the adoption of

6 management control systems for surplus food, as summarized in Table 4.
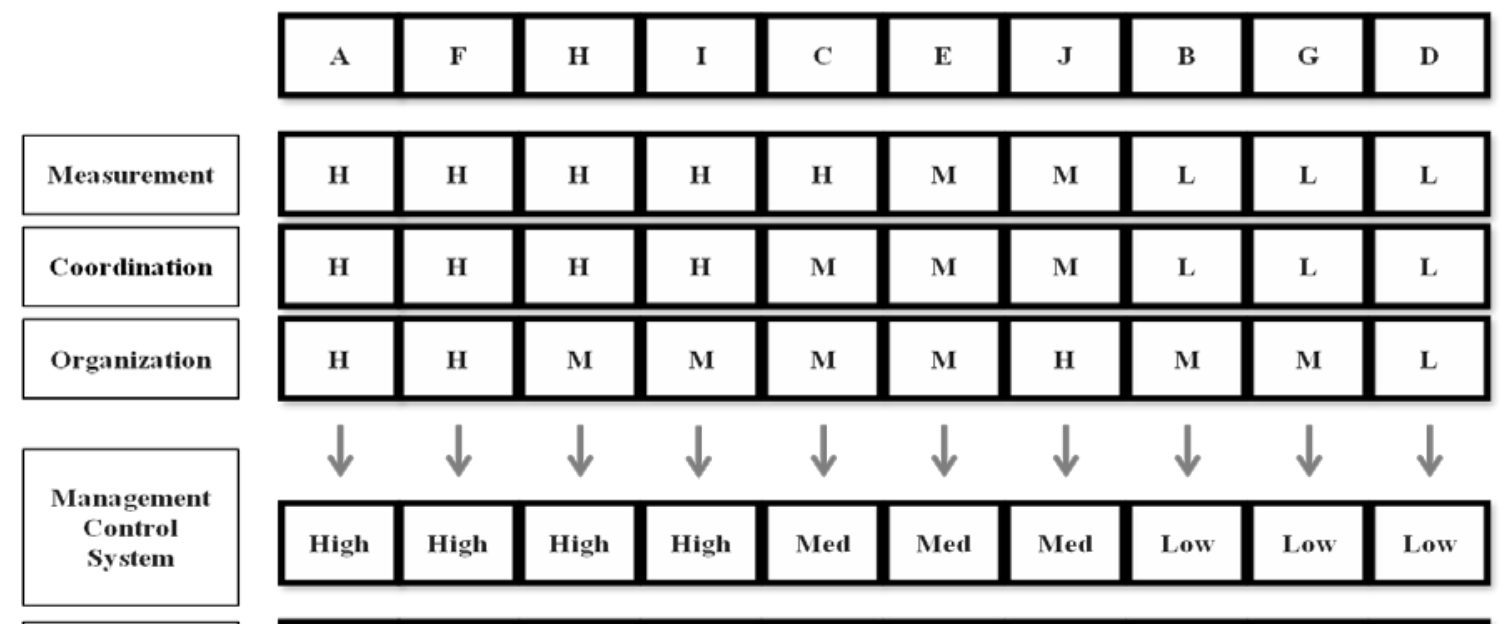

\begin{tabular}{|l|l|l|l|l|l|l|l|l|l|}
\hline$H$ & $H$ & $H$ & $H$ & $H$ & $M$ & $M$ & $L$ & $L$ & $L$ \\
\hline$H$ & $H$ & $H$ & $H$ & $M$ & $M$ & $M$ & $L$ & $L$ & $L$ \\
\hline$H$ & $H$ & $M$ & $M$ & $M$ & $M$ & $H$ & $M$ & $M$ & $L$ \\
\hline
\end{tabular}
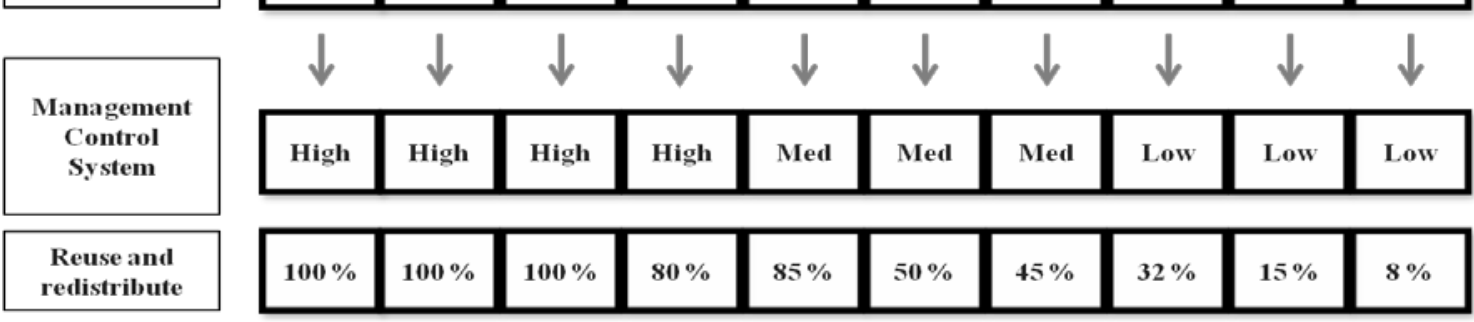

Table 4 shows an apparent exception for some cases. Case $\mathrm{C}$ is a company that produces alcoholic and alcohol-free beverages and soft drinks. Glass bottles are generally used to pack the product. Ruined packaging means, in many cases, that the bottle is broken and the product is no longer fit for human consumption and is thrown away, so there is no surplus. In addition, the products have a relatively long shelf life and this simplifies management, despite there being no well-structured process.

\subsubsection{Partnership with food aid organizations: methods and functions}

In this part, we focused on the organizational and operational drivers, although we do acknowledge that higher level incentives come into play whereby making donations to food aid organizations and acting in partnership with them becomes a valuable option, in the light of corporate social responsibility. Descriptive case studies offered empirical evidence on the internal drivers of surplus food redistribution through donations to food aid organizations (research question (2b)). 
Pro-activism. The company can manage the process proactively or may remain reactive to the demand from food aid organizations.

- Reactive: The food aid organization contacts the company to check if something is available for donation and organizes transport of surplus food (Cases B, D and G).

- Pro-active: The company contacts the food aid organization when there is surplus food to donate (Cases A, C, E. F, H, I and J).

Regularity. The process of making a donation can be regular or variable.

- Sporadic: In most of the cases, when the company detects surplus food to be donated, it contacts the food aid organization for conferment and no formal agreement exists (Cases A, B, C, D, F, G and J)

- Regular: In some cases, there is an agreement between the company and the food aid organization, regulating the process of collecting surplus food, which is defined in advance (Cases E, H and I).

Table 5 compares cases along the two components of the degree of partnership with food aid organizations.

Table 5- Degree of partnership with food aid organizations

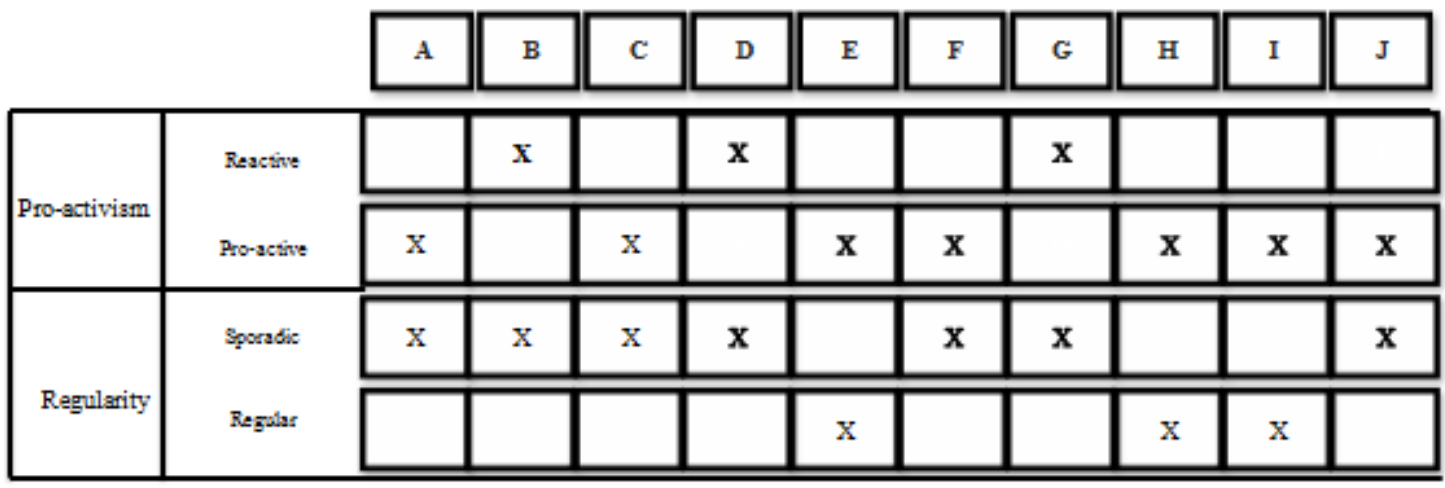

The same method used in Section 4.2.1 was also applied to the remaining two variables that identify the company's partnership with food aid organizations (Table 6). In this case, the comparison was performed by using the percentage of donation to food aid organizations as a measure of effectiveness. In order to perform the cross case analysis, we used the same ordinal scale with three options, Low (L), Medium (M), High (H), to indicate how intensely each factor is implemented by the individual manufacturers. More precisely, we assigned $\mathrm{H}$ if this 
1 relationship is proactive and regular, $\mathrm{M}$ if the relationship is proactive and sporadic and $\mathrm{L}$ if the

Table 6 - Cross case analysis for partnerships with food aid organizations

\begin{tabular}{|l|l|l|l|l|l|l|l|l|l|}
\hline $\mathbf{H}$ & I & A & F & E & J & C & B & G & D \\
\hline
\end{tabular}

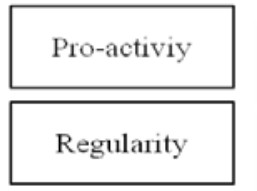

\begin{tabular}{|c|c|c|c|c|c|c|c|c|c|}
\hline $\mathbf{P}$ & $\mathbf{P}$ & $\mathbf{P}$ & $\mathbf{P}$ & $\mathbf{P}$ & $\mathbf{P}$ & $\mathbf{P}$ & $\mathbf{R}$ & $\mathbf{R}$ & $\mathbf{R}$ \\
\hline \hline $\mathbf{R}$ & $\mathbf{R}$ & $\mathrm{S}$ & $\mathrm{S}$ & $\mathrm{R}$ & $\mathrm{S}$ & $\mathrm{S}$ & $\mathrm{S}$ & $\mathrm{S}$ & $\mathrm{S}$ \\
\hline
\end{tabular}
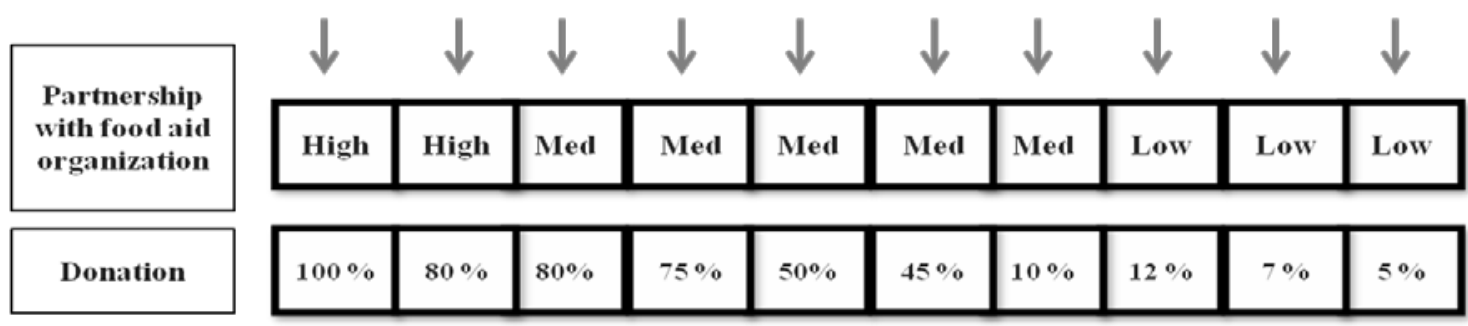

Apart from Case C, the exception here is for Case A. Because of its highly structured management control system, Case A is able to save $100 \%$ of its surplus food and donates $80 \%$ of it. Its relationship with food aid organizations is not regular or formal. However, due its small size, the company is able to manage its surplus food without a regular donation process.

\subsection{Discussion}

The descriptive cases allowed us to adapt the food waste hierarchy to manufacturing, i.e. to address research question 1 . First of all, the cross-case analysis highlighted that reuse of surplus food in primary markets can take different forms, these being remanufacturing, repackaging, promotional sales through discounts and other pricing techniques. In addition to reusing the product, redistribution is also widely practiced, by selling surplus food to secondary markets, distributing it at sponsored events and to employees and, above all, by donating it to food aid organizations. Secondly, the descriptive cases also revealed that the choice among the various management options varies over time, depending upon the feasibility of each single option (the state of the surplus food), but in any case it is moderated by the general attitude of the company towards each option.

Figure 1 shows how the options for managing surplus food and food waste - those available to food manufacturing companies ( $y$ axis) - vary depending on the state of the surplus food, i.e. whether it is suitable for human consumption ( $x$ axis). First of all, not all the surplus food 
management options are available simultaneously. Considering products about to reach their internal sell-by date, in principle the company has a wide portfolio of options when it becomes aware that surplus food is going to be generated (risk identification), as long as it is still fit for human consumption, i.e. it has gone past its use-by date (compliance for human consumption). However, the shelf life requirements included in commercial agreements limit access to primary and secondary markets. Only if surplus food has not exceeded the internal sell-by date accepted by the retail trade and other primary markets (compliance for primary markets), can it be reused, e.g. through special discounts and promotions, or by remanufacturing. Alternatively, it can be redistributed for human consumption in a different form, e.g. donation to non-profit organizations, through internal distribution and product tasting, by sponsoring events or selling to secondary markets. Reuse options cease to be available after the internal sell-by date has expired, but selling to secondary markets may still be a possibility, provided that the surplus food has not gone past the sell-by date accepted by secondary markets (compliance for secondary markets). Other redistribution options remain open for even longer, i.e. until the useby date.

However, Figure 1 highlights that technical and economic feasibility is not the only factor driving choice among the various options. Activating one or another option also depends on the company's overall strategy and its managers' individual motivations. Moreover, if companies work in close partnership with food aid organizations, they are likely to inform food aid organizations about its surplus food distribution plans before it has to comply with secondary markets. For instance, a company may prefer to donate its surplus food for reasons of social responsibility, without considering other reuse and redistribution options, and even without waiting for the surplus food to go over the threshold for secondary markets. Other companies may prioritize economic efficiency and always use commercial options, until the expiration of the sell-by threshold date. 


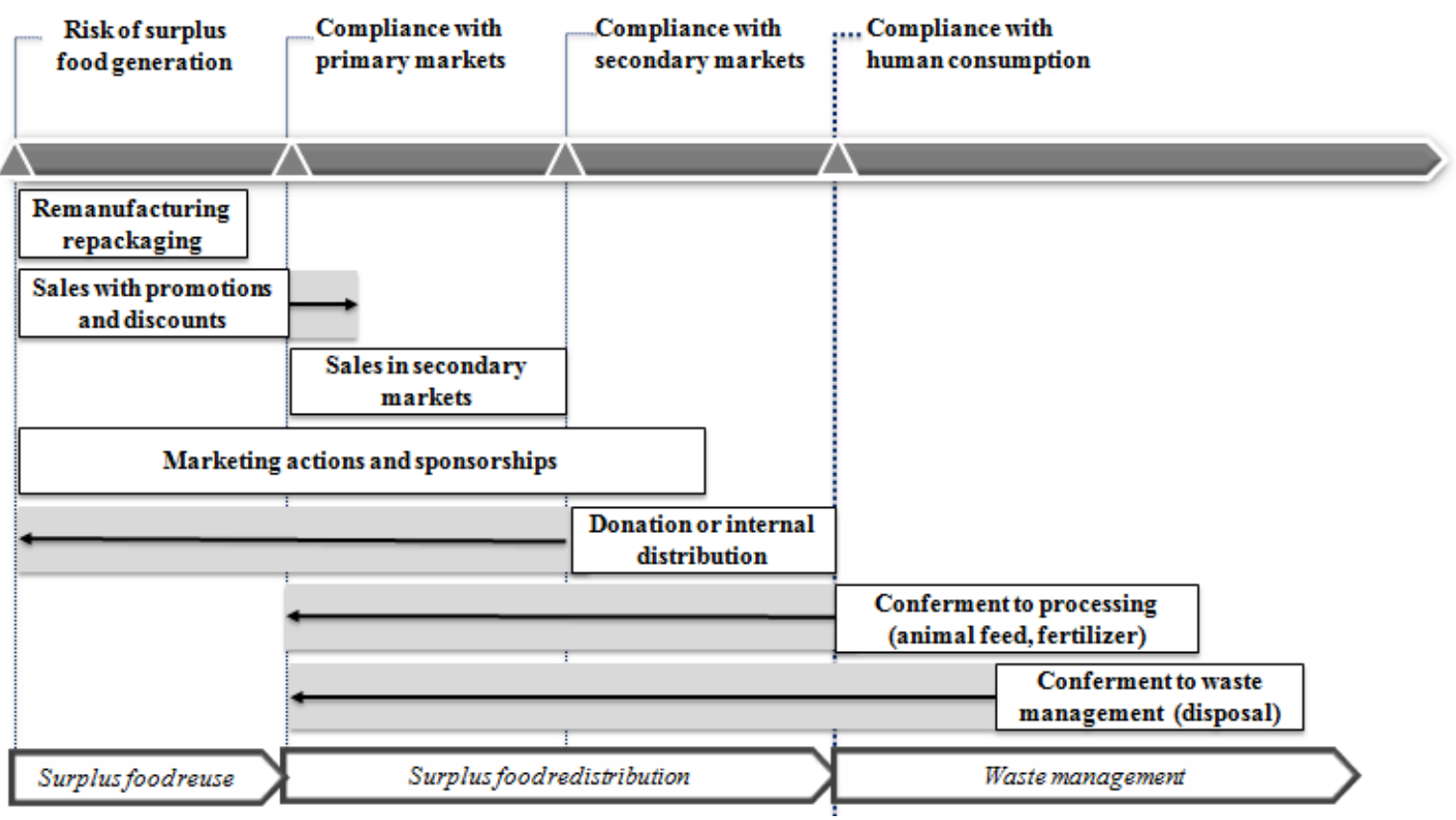

Figure 1 - Surplus food management in food manufacturing companies

The cross case analysis also helped in refining the research question 2 concepts and how they can be adapted to food manufacturing.

The descriptive cases showed that the amount of surplus food reused or redistributed can increase by designing and implementing a structured control system, which includes the measurement of surplus food, coordination among the main officers/departments that have a say on surplus food (from CSR to logistics) and organized management processes. There are differences among the companies, starting from whether there is a system to measure surplus food. While some companies consider surplus food as an important variable in their management control system, and measure it periodically and systematically, other companies are not aware of the issue, and so do not measure surplus food, or do so casually, with negative implications for surplus food uses. Coordination among departments is another factor that reveals how important surplus food management is to the organization. Not only does it focus its employees' attention on the process of managing surplus food, but it also ensures that the process of reusing and redistributing surplus food is more efficient. Finally, the organization of surplus food management entails making a clear distinction between different surplus food types. In order to exploit the different options fully, all the various reasons for why surplus food is generated have to be taken into account; different causes trigger different reuse and redistribution routes. 
1 Donations to food aid organizations are a high-priority channel for redistributing surplus food,

2 and, as such, deserve a more focused analysis. The cases analysed demonstrated that donations

3 risk being sporadic and mainly at the behest of non-profit organizations. A certain amount of activism is demanded of the company, which has to plan its interaction with food banks and charities and give them a clear timescale.

Figure 2 summarizes key factors in surplus food management, grouping them together under "Management Control System", which supports both reuse and redistribution, and "Partnership with food aid organizations”, whereby redistribution through donations is more efficient.

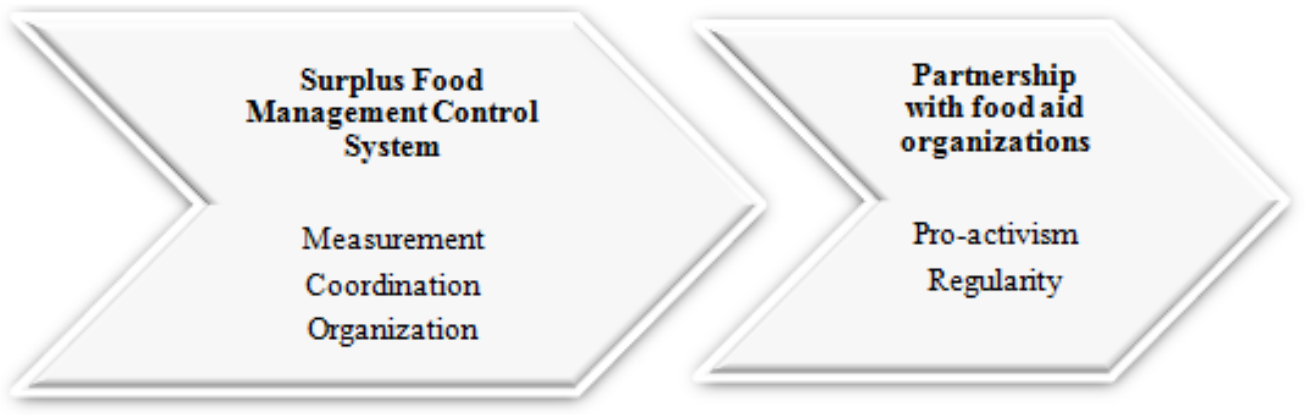

Figure 2 - Critical factors for surplus food reuse and redistribution

\section{Conclusions}

Food waste is a critical issue for the economy, the environment and society. Managing surplus food efficiently and effectively is increasingly recommended when preventing surplus food at the onset is not economically feasible, since it is believed to have huge potential for reducing both food insecurity and food waste. Despite the progressive diffusion of the food waste hierarchy and related guidelines, the management of surplus food in food manufacturing companies is not as straightforward as expected. We, therefore, studied both the various food waste hierarchy options and their feasibility, and the internal barriers and enablers for surplus food management, in particular regarding redistribution for social purposes.

First of all, we found that, once the risk of surplus food is detected, the company can choose among a set of reuse options, depending on the product type and the reason why surplus food is generated. Other channels are remanufacturing, repacking and selling on the primary markets with promotions and discounts. When those options are not viable or are operationally expensive, redistribution options are considered, namely surplus food used for marketing purposes, such as product tasting, sponsorship and distribution to employees. Companies can also make use of the option to donate surplus food to aid organizations. 
1 Secondly, in order to implement the food waste hierarchy fully, the company should plan for the above mentioned process. As a first precondition, it should be aware that surplus food is generated through its own processes. In other words, it should measure the amount of surplus food it generates periodically and in a structured way. At the same time, its decision-making system should be organized to take into account all relevant causes and be coordinated formally. Finally, partnerships with non-profit organizations are necessary to build a formal and regular donation process and increase the amount of surplus food saved for human consumption.

Coming to the limitations of the study, we recognize that our findings may be specific, because they relate to practices observed in one Northern Italian region. Contributions from other countries would allow us to extend the empirical setting, and to understand whether our results can be generalised. We see our current focus on companies that have already donated surplus food - albeit at very different degrees - as necessary at this stage for eliciting best practice. However, we acknowledge that investigating non-donating players and carrying out a quantitative test of our framework on a larger scale could also serve our objective of generalizing the results. Finally, understanding the perspectives of players at different stages in the food supply chain, such as retailers and food service operators, would help in providing a bigger picture.

This research can have implications for other players, besides food manufacturers. For example, non-profit food aid organizations can identify ways for collaborating more easily with donors. They can design solutions to improve their relationship with food manufacturers. Moreover, our results could be the starting point for further research. Policy-makers could evaluate the current incentive system concerning food donations and offer tax incentives to companies that demonstrate to have set up a surplus food management control system, and provide financial support to food aid organizations that give higher priority to the compliant manufacturers among their suppliers.

\section{Acknowledgements}

The authors would like to express their gratitude to the interviewees and colleagues for their contribution to this research, as well as to the Foodsaving project, funded by Cariplo Foundation and Lombardy Region.

\section{References}


1 Aleksandar, C., Smaje, C., 2008. Surplus Food Redistribution: An Analysis of a Third Sector

2 Model. Resource, Conservation and Recycling 52 (11), 1290-1298.

3 Buzby, J., Hyman, J., 2012. Total and Per Capita Value of Food Loss in the United States. Food 4 Policy 37, 561-570.

5 Buzby, J.C.; Bentley, J.T.; Padera, B.; Ammon, C.; Campuzano, J., 2015. Estimated Fresh

6 Produce Shrink and Food Loss in U.S. Supermarkets. Agriculture, 5, 626-648.

7 Darlington, R., Staikos, T., Rahimifard, S, 2009. Analytical Method for Waste Minimization in the Convenience Food Industry. Waste Management 29 (4), 1274-1281.

Edwards, F., Mercer, D., 2007. Gleaning from Gluttony: an Australian youth subculture confronts the ethics of waste. Aust. Geogr. 38, 279-296.

Eisenhardt, K. M., 1989. Building Theories from Case Study Research. The Academy of Management Review 14 (4), 532-550.

Eisenhardt, K. M., Graebner, M. E., 2007. Theory Building from Cases: Opportunities and Challenges, Academy of Management Journal 50 (1), 25-32.

Evans, D., 2014. Food Waste. Home Consumption, Material Culture and Everyday Life. London: Bloomsbury Academic.

Evans, D., Campbell, H. \& Murcott, A. 2012. A Brief Pre-History of Food Waste and the Social

Sciences. Sociological Review, 60, 5-26.

Evans, D., Campbell, H. \& Murcott, A., 2013. Waste Matters: New Perspectives on Food and

Society (D. Evans, H. Campbell, and A. Murcott, Eds.). Oxford: Wiley-Blackwell/ The

Sociological Review.

FAO, 2014. Definitional Framework of Food Loss, SAVE FOOD: Global Initiative on Food Loss and Waste Reduction; Food and Agriculture Organization (FAO), Rome.

FAO, 2015. http://faostat3.fao.org/browse/D/FS/E (accessed 25 May 2015).

Fontana, A., Frey, J.H. 1994. Interviewing: The Art of Science. The Handbook of Qualitative 26 
1 Garnett, T., 2014. Three perspectives on sustainable food security: efficiency, demand restraint,

2 food system transformation. What role for life cycle assessment? Journal of Cleaner Production $373,10-18$.

4 Garrone, P., Melacini, M., Perego, A., 2014a. Opening the Black Box of Food Waste Reduction. $5 \quad$ Food Policy 46, 129-139.

6 Garrone, P., Melacini, M., Perego, A., 2014b. Surplus Food Recovery and Donation: The 7 Upstream Process. British Food Journal 116 (9), 1460-1477.

8 Gentilini, U., 2013. Banking on Food: The State of Food Banks in High-income Countries. 9 Institute of Development Studies, Brighton.

Griffin, M., Sobal, J., Lyson, T., 2009. An Analysis of a Community Food Waste Stream. Agriculture and Human Values 26, 67-81.

Gustavsson, J., Cederberg, C., Sonesson, U., 2011. Global Food Losses and Food Waste. Food and Agriculture Organization of United Nations, Rome.

Kantor, L., Lipton, K., Manchester, A., Oliviera, V., 1997. Estimating and Addressing America's Food Losses. Food Review, 2-12.

Katajajuuri, J., Silvennoinen, K., Hartikainen, H., Heikkila, L., 2014. Food Waste in the Finnish Food Chain. Journal of Cleaner Production 73, 322-329.

Kummu, M., De Moel, H., Porkka, M., Siebert, S., Varis, O., Ward, P.J., 2012. Lost Food, Wasted Resources: Global Food Supply Chain Losses and Their Impacts on Freshwater, Cropland, and Fertiliser Use. Science of Total Environment , 477-489.

Lundie, S., Peters, G. M, 2004. Life Cycle Assessment of Food Waste Management Options. Journal of Cleaner Production 13 (3), 275-286.

Mena, C., Adenso-Diaz, B., Yurt, O., 2011. The Causes of Food Waste in the Supplier - Retailer Interface: Evidences from the UK and Spain. Resources, Conservation and Recycling 55 (6), 648-658.

Mirabella, N., Castellani, V., Sala, S., 2013. Current Options for the Valorization of Food Manufacturing Waste: A Review. Journal of Cleaner Production 65 (15), 28-41. 
1 O'Connor. C. 2013. Quantification of Food Waste in the EU. OECD Food Chain Network. 2 http://www.oecd.org/site/agrfcn/Session\%201_ClementineOConnor.pdf (accessed 25 May 3 2015).

4 Papargyropoulou, E., Lozano, R., Steinberger, J. K., Wright, N., 2014. The Food Waste 5 Hierarchy as a Framework for the Management of Food Surplus and Food Waste. Journal of 6 Cleaner Production 76, 106 - 115.

7 Richter, B., Bokelmann, W., 2016. Approaches of the German food industry for addressing the 8 issue of food losses. Waste Manag. 48, 423-429.

9 Santini, C., Cavicchi , A., 2014. The Adaptive Change of the Italian Food Bank Foundation: A 10 Case Study. British Food Journal, 116 (9), 1446 - 1459.

11 Schneider, F., 2013. The evolution of food donation with respect to waste prevention. Waste 12 Manag. 33, 755-763.

13 Thyberg, K.L., Tonjes, D.J., 2016. Drivers of food waste and their implications for sustainable policy development. Resour. Conserv. Recycl. 106, 110-123.

15 Voss, C., Tsikriktsis, N., Frohlich, M., 2002. Case Research in Operations Management, 16 International Journal of Operations \& Production Management, 22 (2), 195-217.

17 Yin, R., 2003. Case Study Research Design and Methods. Sage Publications, London. 